\title{
Dynamic Pricing under Cost Reduction in the Presence of Myopic and Strategic Consumers
}

\author{
Guangning Liu $(\mathbb{D}$, Zhenzhong Guan $\mathbb{D}$, and Hua Wang $\mathbb{D}$ \\ School of Economics and Management, Southwest Jiaotong University, 111 North 2nd Ring Road, Chengdu 611756, China \\ Correspondence should be addressed to Zhenzhong Guan; zzguan@swjtu.cn
}

Received 20 February 2019; Accepted 27 March 2019; Published 25 June 2019

Academic Editor: Juan L. G. Guirao

Copyright (C) 2019 Guangning Liu et al. This is an open access article distributed under the Creative Commons Attribution License, which permits unrestricted use, distribution, and reproduction in any medium, provided the original work is properly cited.

\begin{abstract}
After release, a product usually suffers cost reductions during its whole lifespan. Compared to the myopic, strategic consumers may have stronger incentive to delay the purchase once they perceive that a significant cost reduction will result in a markdown. The strategic (compared to the myopic) properties influence the seller both quantitatively in terms of proportion of strategic consumers and qualitatively in terms of customer patience. To forecast the reaction of the whole market under cost reduction, it is necessary to acquire the strategic properties. In this paper, we study the impacts of proportion of strategic consumers, customer patience, and cost reduction on dynamic pricing strategy when cost reduction comes from technology advancement. The seller makes pricing strategies when facing unknown future cost, and the buyer makes purchase decisions when facing unknown future price. Our study shows that generally both higher strategic consumer proportion and customer patience contribute to a delay in sales. Further, profit diversion happens under great combination of strategic properties. In addition, with the increase of customer patience, not only strategic but also myopic consumers will buy less. Finally, the strategic properties moderate the pricing strategy in latter stage when there is a cost reduction. This indicates a threshold as combination of strategic properties, upon which seller tends to offer a smaller markdown to discourage strategic waiting, and under which seller tends to offer a greater markdown to divert strategic consumers to the latter period.
\end{abstract}

\section{Introduction}

Have you bought the recently released Huawei Mate 20 Pro? The new generation of Huawei's flagship, Huawei Mate Series, had been unveiled on October 16, 2018, in London as it is reported by Joseph [1]. Also after this release, there exists a sharp price drop of $25 \%$ on the elder generation Mate 10 . On the one hand, it may be a common measure to stimulate demand under the release of a new generation. On the other hand, the price drop may be out of cost reduction, which is on the basis of technology advances during the whole life circle of the product. And this kind of effort of Huawei on technology advancement had also been reported on Reuters by Eric [2]. Anyway, the sharp price drop always attracts the customers who are waiting for it.

There commonly exist two types of consumers in the market, according to Levin [3]. One is the myopic consumer who makes a purchase decision as long as the price tag is lower than his valuation for the product despite the potential markdown on price in the future. This supposition contributes to tractable models and significantly handy analysis and leads to transparent properties for dynamic pricing strategies. The other type is strategic consumer, like the one waiting for the price cut of elder Huawei Mate 10. That is, strategic consumers not only decide whether to buy depending on the present valuation and price, but also time their purchase strategically to maximize their consumer surplus. In fact, the market is usually the mixture of these two kinds of people. This compels researchers to take proportion of strategic consumers (the ratio of strategic consumers to the whole market) into consideration, like Li [4]. Further, delaying purchase in anticipation of price reductions also has a bad influence as it sacrifices present usage and current value. This forces scholars to include the discount factor into the trade-off between purchase stages, which habitually appeared as customer patience in [5] by Shum.

Huawei may hope a sale boom of the new smart phone and they decide to turn down the price of Mate 10 to give 
road of it. However, cost reduction, arising from technology advances, also plays an important role in price cut. President of HUAWEI Business Group, Yan, stated that Huawei has invested more than 400 billion Yuan on R\&D in the last ten years as reported by Zhang [6]. This type of cost reduction, which we call technology advancement effect, is independent of previous production quantity, compared to production learning effect. The technology advancement effect is usually pretended as an exogenous variable, and on the contrary, the production learning effect is always treated as the endogenous one. Production learning comes from learning by doing according to Shum [5], and this kind of cost reduction increases with the first-period production quantity. Furthermore, it is vital for worker training by which the production process is easier to control and production technics is easier to master. Additionally, it is necessary to emphasize that, under the case of production learning, the production quantity is usually not transformed into inventory.

In this paper, we both study the firm's pricing strategies and consumers purchase decisions under dynamic pricing. This pricing strategy gives a high degree of flexibility which distinguishes it from the price commitment and price matching. Further, the dynamic pricing strategy also comes as the most common strategy in practice. From the demand side, we consider a mixture market of both strategic and myopic customers, and there exist product availability and purchasing opportunities in both periods. Also from the supply side, the seller as the monopoly controls the pricing power, and out of dynamic pricing case he also has the absolute freedom of two-period pricing without any extra cost and constraints.

We also consider the incentives by cost reduction. For buyers, especially the strategic ones, cost reduction may give rise to the motivation of waiting, because they expected a higher price cut in the latter period. And for the seller, cost reduction may also contribute to the delay of sales, because there exists a higher profit margin in the latter period.

In particular, we analyze the impact of strategic properties and cost reduction. We study the strategic properties from two dimensions: proportion of strategic consumers and customers patience. These properties indicate the influences on the seller both quantitatively in terms of proportion of strategic consumers and qualitatively in terms of customer patience. As for the cost reduction which is mainly from the technology advancement, we analyze the influence of cost reduction separately and study strategic properties and cost reduction effect mutually to see if there exists some mediating or moderating effect. Apart from that, we study the robustness of optimal pricing strategies, sales, and expected profit.

Our analysis leads to several interesting insights. First, we have investigated the impact of strategic properties on pricing, sales and expected profit. From the demand side, a high proportion of strategic consumers contributes to the delay of purchase, which is manifested as the demand decrease in the first period and increase in the second period. Further, from the supply side, when observing this delay, the seller tends to adjust pricing strategy to remedy this trend. As a result, the profit decreases. These serial reactions also happen on the customer patience. However, when these come to the customer patience, some counterintuitive results come into being. According to our analysis, the strengthening customer patience which as a property belonging to strategic consumers can also lead to the decrease in myopic demand.

Apart from that, when facing great enough proportion of strategic consumers (or customer patience), there exists a profit diversion, which means the main profit sources from the latter period. And when profit diversion happens, the seller has to pay more attention to the second stage, and out of the flexibility of dynamic pricing, the seller may be more lucrative than in other pricing strategies, like price commitment and price matching.

In addition, a significant cost reduction induces more strategic waiting, which is consistent with our common sense. Further, the technology advancement may always increase the expected profit, when we have not taken into consideration the expense of R\&D. (The simplified analysis including the TA expenses has also been conducted in Appendix B. This analysis also indicates a proper TA is reasonable.)

Besides, contrary to conventional wisdom, an intensified cost reduction does not always depress the second-period price. Rather, there exists a threshold under cost reduction. Seller tends to offer a smaller markdown in case of the combination of strategic properties upon it and a greater one otherwise.

This paper is organized as follows. Section 2 reviews the former literature. Section 3 introduces our model. Section 4 analyzes the equilibrium under the impact of strategic properties and cost reduction. Section 5 provides conclusion remarks.

\section{Literature Review}

Our paper relates to several bodies of research: the literature on dynamic pricing, strategic properties, and the literature on cost reduction.

There exists a notable success on dynamic pricing and revenue management. Starting from Gallego and van Ryzin [7], more studies pay attention to stochastic models with a Poisson arrival of myopic consumers. On the contrary, researchers try to take strategic consumers into consideration, which makes monopolistic pricing model more complicated. Thus, a deterministic model is often derived, like the one in the research of Besanko and Winston [8]. This model depicts a dynamic programming procedure to compute the dynamic pricing strategy including rational behavior. Su [9] investigates intertemporal pricing strategy within a market containing both strategic and myopic consumers and by high-valuation and low-valuation segments. Customers in this study arrive continually among the duration of the selling period. This article concludes when the seller should use markdown. Xiong [10] designs a dynamic programming model within a continuous-time Markov decision process to study a remanufacturing problem in the presence of random price-dependent returns and random demand. In the following studies of dynamic pricing strategy when facing forward-looking consumers, Aviv and Pazgal [11] study the 
optimal dynamic pricing strategies of fashion-like seasonal products and make a comparison between strategic and myopic consumers. Liu and van Ryzin [12] figure out that the strategic capacity rationing induces early purchases under dynamic pricing strategies. Furthermore, the studies start to include products quality in dynamic pricing questions. $\mathrm{Li}$ [13] builds a two-stage dynamic pricing model to investigate the online video service and it shows that pricing strategy is affected by videos available time and borrower's emotional factor. Furthermore, the recent development in applied mathematics, for example, Pandey [14] and Navarro [15], also stimulates the further studies in dynamic pricing.

In addition to the studies on dynamic pricing strategies when facing strategic consumers like Levin [3], price commitment is also a common pricing strategy in revenue management. Su and Zhang [16] indicate that promising can improve expected profit which includes not only quantity commitment but also pricing commitment. This commitment induces consumers to make the purchase decision earlier at a relatively high price maintaining the exclusivity of the product. This commitment solves the challenge from strategic consumers to contract which usually exists in newsvendor problem. As we all know, it is essential for a supply chain to build contractual relationship between retailers and suppliers, which can eliminate double marginalization by cooperating firm's goals. Cachon [17] gives detailed analysis on supply chain coordinating, in particular by contracts. But troublesome happens when facing the strategic consumers, because "the centralized optimal solution benchmark may not be appropriate anymore" in Su's [9] explanation.

Compared with the two strategies above, price matching becomes more cordial to consumers when seller guarantees to reimburse the price difference to a consumer who buys a product before the seller marks it down. This posterior price matching policy is associated with strategic consumers by Lai [18]. Under his study, PM policy weakens strategic consumers' waiting incentive and thus helps the seller to raise price in regular selling season. However, the research on PM policies has been mainly conducted in economics and marketing, which aims to advance in competition. The literature was initiated by Salop [19], Holt and Scheffman [20], and Png and Hirshleifer [21]. They describe the function of PM policy on competition. Further, the recent study on PM policy can also be seen in Chen [22] and Kukar [23].

The additional studies of strategic consumers to dynamic pricing begin from the study of Besanko and Winston [8], which was addressed before. There must be some properties that distinguish them from myopic ones. Myopic consumers only have one decision: whether to purchase. However, the strategic consumers have the additional one: when to purchase. This distinction appears in [24] by Prasad. Apparently, the strategic consumers are born to have the additional choice. However, the strategic waiting still has expenses. The strategic consumers entering the market make the decision either to purchase under current price, to leave the system, or to wait for a more attractive price. Further, if they choose to wait, customers incur waiting cost in [9] by Su. This waiting cost is usually depicted as customer patience. On the other hand, mixed market with both strategic and myopic customers is common in former studies. This induces the consideration of consumer constituent. Kremer [25] proposes a theory and conducts an experiment under dynamic pricing in the presence of both strategic and myopic consumers. The proportion of strategic consumers moderates the optimal pricing strategy, and similar results were found in the survey in air-travel industry by Li et al. [4]. Besides, Shen and Su [26] introduce modeling in revenue management and auctions with consideration of consumer behavior. Also, more and more researchers in revenue management, especially dynamic pricing, bring strategic properties into their papers, like Levin [3].

Cost reduction also plays an important role in our paper. According to the description by Shum et al. [5], cost reduction has mainly two dimensions: technology advancement and production learning. For technology advancement, there is no relationship with the first-period production quantity under the case of dynamic pricing, whereas for the production learning effect there is. Further, the former papers mostly concentrate on the production learning effect. The production learning effect first appears in a paper by Arrow [27]. Empirical studies mainly pay attention to measure how significant the production learning effect is, for example, Rosen [28] and Pruett [29]. On the analytical side, researchers also perform a lot of models to depict the influence of production learning effect, such as Jin [30] and Terwiesch [31]. Different from production learning effect, technology advancement usually happens without relation to production quantity. There are less papers on technology advances in production, but more on competition, like the one by Erat [32].

In this paper, we investigate the cost reduction impact on the market containing both myopic and strategic consumers under dynamic pricing. First, different from most former studies in dynamic pricing area, we take both strategic and myopic consumers into consideration, which fits more conventional wisdom. Further, we derive a model picturing the strategic consumers from two dimensions, proportion of strategic consumers and customer patience, and also analyze the joint influence of them. In addition, apart from the strategic influence on sellers, we also perform the strategic influence on nonstrategic (myopic) consumers. And the additional consideration of cost reduction to dynamic pricing is not included in most former researches. This cost reduction arising from technology advances also plays a very important role in decisions of both supply and demand sides.

\section{Model Description}

This paper considers a monopolistic firm who sells product to a market with a mass of infinitesimal consumers over two periods. Without loss of generality, we assume that the market size is determined and normalized to 1 . We assume that valuation of customers $v$ is distributed uniformly on the interval $[0,1]$. And each consumer can buy no more than one unit of product.

We consider our problem when facing both myopic and strategic consumers, and we assume the proportion of strategic consumers as $\theta \in[0,1]$ and then the proportion of 
TABLE 1: Demand (sales) to each consumer segment by period.

\begin{tabular}{lcr}
\hline & First period & Second period \\
\hline Myopic demand & $Q_{1}^{m}=(1-\theta)\left(1-p_{1}\right)$ & $Q_{2}^{m}=(1-\theta)\left(p_{1}-p_{2}\right)$ \\
Strategic demand & $Q_{1}^{s}=\theta(1-\bar{v})$ & $Q_{2}^{s}=\theta\left(\bar{v}-p_{2}\right)$ \\
Total demand & $Q_{1}=1-(1-\theta) p_{1}-\theta \bar{v}$ & $Q_{2}=(1-\theta) p_{1}+\theta \bar{v}-p_{2}$ \\
\hline
\end{tabular}

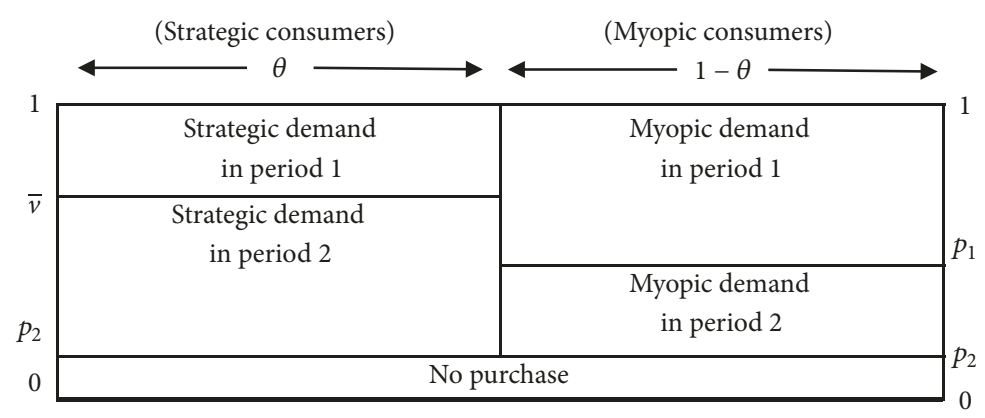

FIGURE 1: Customer segmentation between strategic and myopic customers.

myopic as $1-\theta$. Each customer takes the purchase decision and the firm decides the two-stage prices, denoted by $p_{i}, i=$ 1,2 . While myopic consumers simply decide whether or not to buy, consumers behaving strategically will also take into account when to buy, similar to the description by Shum et al. [5]. We also assume that strategic customers discount future utility by a factor $\delta \in(0,1)$; that is, when a customer has valuation $v$, the utility for him to wait until the latter period is $\delta\left(v-p_{2}\right)$. This factor is also used by Aviv and Pazgal [11] and Besanko and Winston [8].

The selling season can be divided into two periods and the firm chooses dynamic pricing strategy to implement. With dynamic pricing, the prices are declared at the beginning of each period, in order to maximize the firm's profit to go, which is from Aflaki [33]. With generality, the firm is risk neutral and makes pricing decisions to maximize its total profit. In addition, we assume that the production cost is fixed at $c \in(0,1)$ in the former period; however, the cost will be depreciated in second period. In particular, the cost reduction is mainly from technology advancement. As a result, the actual cost in the beginning of the latter stage will be at $c-\alpha$, where we use $\alpha \in(0,1)$ to represent the TA (technology advancement) effect, the same as the assumption by Shum et al. [5].

This paper takes into consideration both myopic and strategic consumers, which can also be seen in former papers, like those by Su [9] and Cachon and Swinney [34]. However, there are also some studies only concentrating on strategic consumers, like those by Liu and Van Ryzin [12] and Shum [5]. Among pricing strategies, dynamic pricing is the most flexible one. It provides the flexibility to determine later price without any commitment to consumers. Prior researches include those by Shum [5] and Kremer [25].

Under dynamic pricing strategy, we solve this problem backward by first analyzing the optimal price in the second period. A myopic consumer makes purchase decision on whether the posted price is below his valuation in each period.
Lemma 1. Aware of early price $p_{1}$, strategic consumers expect the price $p_{2}\left(p_{1}\right)$ in the second season. There exists $a \bar{v}=$ $\min \left\{1,\left(p_{1}-\delta p_{2}\left(p_{1}\right)\right) /(1-\delta)\right\}$ such that strategic consumers with $v<\bar{v}$ will wait until the second period and strategic consumers with $v>\bar{v}$ will make purchase decision in the first period.

The proofs of all lemmas appear in Appendix A. Note that whenever $\bar{v}=1$, no strategic consumers are buying in the early season. According to Lemma 1, a strategic consumer will buy a product in the early period if his immediate consumer surplus $v-p_{1}$ exceeds the discounted expected surplus $\delta(v-$ $p_{2}$ ) in later period; and he will make purchase decision in second stage otherwise.

We use Table 1 and Figure 1 to conclude the demand (sales) for each consumer segment by season. Suppose strategic consumers with valuation higher than $\bar{v}$ are going to purchase in the first stage; we can get the critical condition of strategic consumer's valuation,

$$
\bar{v}-p_{1}=\delta\left(\bar{v}-p_{2}\right) .
$$

Also the demand of first period is $Q_{1}=1-(1-\theta) p_{1}-\theta \bar{v}$, and the demand of second period is $Q_{2}=(1-\theta) p_{1}+\theta \bar{v}-p_{2}$. The firm's expected profit in the second period is

$$
\pi_{2}=\left[\theta\left(\bar{v}-p_{2}\right)+(1-\theta)\left(p_{1}-p_{2}\right)\right]\left(p_{2}-c_{2}\right) .
$$

We take the second derivative of second-period profit $\pi_{2}^{\prime \prime}\left(p_{2}\right)<0$, which means that $\pi_{2}$ is concave in $p_{2}$, so the first-order condition gives rise to the optimal strategy,

$$
p_{2}^{*}(\bar{v})=\frac{1}{2}\left[(1-\theta) p_{1}+\theta \bar{v}+c_{2}\right] .
$$

From above, we can get the critical strategic consumers' valuation between two purchasing periods

$$
\bar{v}=\min \left\{1, \frac{[2-\delta(1-\theta)] p_{1}-\delta c_{2}}{2(1-\delta)+\delta \theta}\right\} .
$$


Denote $v_{E}=\left([2-\delta(1-\theta)] p_{1}-\delta c_{2}\right) /(2(1-\delta)+\delta \theta)$. Through the analysis above, we know the firm's total expected profit in case of both myopic and strategic consumers during two operational phases

$$
\begin{aligned}
& \pi^{*} \\
& = \begin{cases}\left(p_{1}-c\right)\left(Q_{1}^{m}+Q_{1}^{s}\right)+\left(p_{2}-c_{2}\right)\left(Q_{2}^{m}+Q_{2}^{s}\right), & \text { if } v_{E}<1 ; \\
\left(p_{1}-c\right)\left(Q_{1}^{m}\right)+\left(p_{2}-c_{2}\right)\left(Q_{2}^{m}+\theta\left(1-p_{2}\right)\right), & \text { if } v_{E} \geq 1 .\end{cases}
\end{aligned}
$$

We denote the optimal profit as $\pi_{2 s}$ when $v_{E}<1$, and as $\pi_{1 s}$ when $v_{E} \geq 1$.

When there is cost reduction in the beginning of second period, the cost in the second period is $c-\alpha$, and we have to consider the consumer purchase strategy, firm's optimal pricing, and profit. Further, we will give more details on the impact of the cost reduction due to technology advances in next section.

\section{Equilibrium under Dynamic Pricing}

In this section, we study the firm's pricing strategy and profit and characterize the impact of several important parameters. Also, we show the difference between the basic case and the one under cost reduction, which results from technology advancement.

On the one hand, both strategic and myopic consumers would conduct their purchase decision in both periods, when $\bar{v}<1$. Under dynamic pricing, which is prevailing both in research and practice, the firm's total expected profit should be solved backward by first analyzing the optimal price in the second period,

$$
p_{2}^{*}(\bar{v})=\frac{1}{2}\left[(1-\theta) p_{1}+\theta \bar{v}+c-\alpha\right],
$$

where $\bar{v}=\left((2-\delta(1-\theta)) p_{1}-\delta(c-\alpha)\right) /(2(1-\delta)+\delta \theta)$, in this cost reduction situation, and the firm's total profit.

$$
\begin{aligned}
& \pi_{2 s}\left(p_{1}\right) \\
& =\frac{\left(c-p_{1}\right)\left(\delta \theta\left(\alpha-c+2 p_{1}-1\right)-2 \delta p_{1}+2 \delta+2 p_{1}-2\right)}{\theta \delta-2 \delta+2} \\
& \quad+\frac{(\theta \delta-\delta+1)^{2}\left(\alpha-c+p_{1}\right)^{2}}{(\theta \delta-2 \delta+2)^{2}}, \\
& \text { s.t. } \frac{[2-\delta(1-\theta)] p_{1}-\delta(c-\alpha)}{2(1-\delta)+\delta \theta}<1
\end{aligned}
$$

The condition above equals $v_{E}<1$, which guarantees that the strategic consumer's purchase happens in both periods. That is to say, when the critical valuation is greater than 1 , the strategic consumers will only purchase in the second period.

The second derivative of the two-period profit $\pi_{2 s}^{\prime \prime}\left(p_{1}\right)<$ 0 , which means that $\pi_{2 s}$ is concave in $p_{1}$. By using the firstorder condition, we can get first-period optimal price $p_{1}^{*}$. After that, we can also form the second-period optimal price $p_{2}^{*}$.
Proposition 2. Optimal pricing and expected profit for the seller under different critical valuations:

(1) When $v_{E} \geq 1$, the optimal pricing for the seller is $\left\{p_{1,1 s}^{*}\right.$, $\left.p_{2,1 s}^{*}\right\}=\{(c+\theta+\alpha+2) /(\theta+3),(2 c+(1+\theta)(1-\alpha)) /(\theta+3)\}$, and the seller's expected maximum profit can be formed as $\pi_{1 s}^{*}=$ $\left(\alpha^{2}+(1-c)^{2}+(1+\theta)(1-c)\right) /(\theta+3)$.

(2) When $v_{E}<1$, the optimal pricing for the seller is $\left\{p_{1,2 s}^{*}, p_{2,2 s}^{*}\right\}=\left\{\left(N_{1} \alpha+N_{2} c+N_{3}\right) / 2(\delta \theta-\delta+1)(\delta \theta-3 \delta+\right.$ $\left.3),\left(N_{4} \alpha+N_{5} c+\theta \delta-2 \delta+2\right) / 2(\theta \delta-3 \delta+3)\right\}$, and the seller's expected maximum profit can be formed as $\pi_{2 s}^{*}=\left(c^{2}(\delta \theta-2 \delta+\right.$ $\left.\left.2)^{2}+c\left(2 \delta^{2} \theta^{2}+(\delta+2) M_{1}\right)+\left(\alpha^{2} M_{2}+(\alpha+1) M_{3}-\delta^{2} \theta^{2}\right)\right)\right) / 4(\delta \theta-$ $3 \delta+3)(\delta \theta-\delta+1)$, where $N_{1}=\delta^{2} \theta^{2}-2 \delta^{2} \theta+2 \delta^{2}+2 \delta \theta-4 \delta+2$, $N_{2}=\delta^{2} \theta^{2}-4 \delta^{2} \theta+2 \delta^{2}+4 \delta \theta-4 \delta+2$, and $N_{3}=\delta^{2} \theta^{2}-$ $4 \delta^{2} \theta+4 \delta^{2}+4 \delta \theta-8 \delta+4 ; N_{4}=\theta \delta+2 \delta-2, N_{5}=\theta \delta-4 \delta+4$; $M_{1}=-2 \delta^{2} \theta^{2}+4 \delta^{2} \theta-4 \delta \theta-4 \delta^{2}+8 \delta-4, M_{2}=5 \delta^{2} \theta^{2}-8 \delta^{2} \theta+$ $4 \delta^{2}+8 \delta \theta-8 \delta+4$, and $M_{3}=2 \delta^{2} \theta^{2}-4 \delta^{2} \theta+4 \delta^{2}+4 \theta \delta-8 \delta+4$. (Note that $v_{E}=\left([2-\delta(1-\theta)] p_{1}-\delta c_{2}\right) /(2(1-\delta)+\delta \theta)$, and all surrogate parameters above mainly consist of strategic consumers proportion $\theta$ and the consumer patience $\delta$.)

On the one hand, the strategic consumers may not purchase in the first period when the critical valuation $v_{E} \geq 1$. The expected profit is $\pi_{1 s}=\left(p_{1}-c\right)\left(Q_{1}^{m}\right)+\left(p_{2}-c_{2}\right)\left(Q_{2}^{m}+\theta(1-\right.$ $\left.\left.p_{2}\right)\right)$. We conduct the second derivative of profit $\pi_{1 s}^{\prime \prime}\left(p_{1}\right)<0$ and $\pi_{1 s}^{\prime \prime}\left(p_{2}\right)<0$, which implicate that $\pi_{1 s}$ is concave in both $p_{1}$ and $p_{2}$. By using the first-order condition, we get twoperiod optimal price $p_{1}^{*}$ and $p_{2}^{*}$.

On the other hand, when facing the strategic demand only in the second period, we can just treat this single-period demand as myopic. In other words, there exists no strategic waiting in single period, and this can also be reflected in our result of expected profit where there is no parameter of consumer patience.

This phenomenon makes the decision process easier, and seller can make a more identical strategy. However, we should also be aware of the common ground with the previous situation. That is, there still exists myopic demand in the first period in this paper, which means the company should adopt two-period pricing policy to maximize the total profit. Next, we will further discuss our findings on the critical condition of whether strategic consumers purchase in both periods.

Note that we factor the condition of $v_{E}$ and find that strategic consumers will buy in both periods if $\alpha /(1-c)<$ $\left(\delta^{2} \theta^{2}+\delta^{2} \theta-2 \delta^{2}+2 \delta \theta+2\right) /\left(\delta^{2} \theta^{2}-5 \delta^{2} \theta+4 \delta^{2}+4 \delta \theta-6 \delta+2\right)$, and only in the second period otherwise.

From this condition, we can see that the left side is obviously increasing in both $\alpha$, the technology advancement effect, and $c$, the variable cost before technology advances. This indicates that greater technology advancement and higher variable cost will delay the purchase of strategic consumers. Due to TA effect, strategic consumers would like to wait and expect a markdown in the second period and then make their tradeoffs. However, the higher variable cost may lead to the price of first stage going up, because of which less strategic consumers would buy the products in the former stage.

On the other hand, the myopic demand has a close relationship with the two-period price and seems more 
steady. However, the TA effect and initial cost may have a mediation effect on myopic demand by pricing.

Differentiated from the market only with strategic consumers, in our study, the seller still has two periods of decision. And the marginal profit within two periods differs. This implicates that there is still a necessity to combine pricing policies to maximize the total profit.

4.1. Impact of Cost Reduction. Now we turn to the influence of cost reduction under dynamic pricing strategy. Cost reduction may come from a reduction in the variable cost with technology improvement. This kind of cost reduction is independent of sales in the former period. In this section, we consider the impact of cost reduction on pricing policy and expected profit in Proposition 3 and sales in Proposition 4.

Proposition 3. Impact of technology advancement $\alpha$ on firm's pricing and expected profit:

(1) For the optimal price in the first stage, $\partial p_{1}^{*} / \partial \alpha>0$, while for the optimal price in the second period, $\partial p_{2}^{*} / \partial \alpha>0$ when $\theta>2(1-\delta) / \delta$, and $\partial p_{2}^{*} / \partial \alpha \leq 0$ when $\theta \leq 2(1-\delta) / \delta$.

(2) For the firm's expected profit, $\partial \pi_{2 s}^{*} / \partial \alpha>0$.

When there exists cost reduction, the firm always has a strong incentive to stimulate the later demand because of the higher marginal profit in the second period when facing technology advancement. So it is easy to understand why sellers tend to increase the first-period price. However, this results in the second-period pricing strategy bias. In other words, the optimal price in the second period is conditionally increasing in $\alpha$ (or conditionally decreasing in $\alpha$ ).

We select different value of $\delta$ and $\theta$ to derive the indifference curve of the condition which reverses the optimal pricing trend in the second period. When satisfying the condition $\theta<2(1-\delta) / \delta$ (or Area 1 ), seller should lower the price, and when $\theta>2(1-\delta) / \delta$ (or Area 2 ), seller should raise the price.

When facing the cost reduction in the latter period, the firm normally increases the first-period price to make much demand shift from period 1 to period 2. Then the secondperiod market will reach a new equilibrium where demand becomes higher and price becomes lower compared with the former equilibrium. These ordinary changes can always be read in managerial economic books, such as Png [35]. Nevertheless, our finding seems to be counterintuitive. That is, raising second-period price is not always the optimal strategy in the reaction of the cost reduction. However, it depends. When the proportion of strategic consumers in the market is less than the criteria, $\theta<2(1-\delta) / \delta$, the increase of cost reduction will push the seller to lower the price; when it is more than that, $\theta>2(1-\delta) / \delta$, the increase of cost reduction will motivate the seller to raise the price. And this critical boundary has been illustrated in Figure 2. Or we can conclude it as increase of the second-period price depending on the constituent of consumers. Therefore, it is vital for the company to figure out the constituent before making the second-period pricing strategy.

Another observation is that no matter what the proportion of strategic consumers in the market is, the total profit is

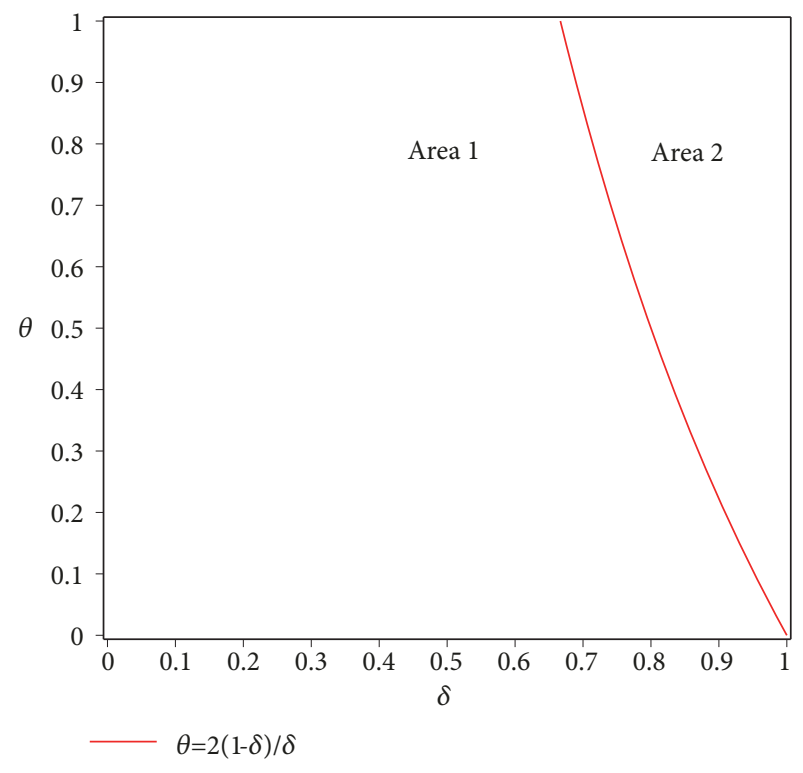

FIGURE 2: Second-period pricing strategy with condition under cost reduction. Note. Area $1, \theta<2(1-\delta) / \delta$; Area $2, \theta>2(1-\delta) / \delta$.

always ascendant with the rise of technology advancement. On the one hand, the increasing trend of profit is not surprising, because the technology advancement improves the marginal profit. On the other hand, it is a little out of common sense that the firm should implement the technology innovation as possible as it can. The reason is that we do not take the expense of technology advancement (used to be fixed cost) into consideration. If we add the fixed cost $f_{c}$ to the profit condition, then the result would differ. When considering the fixed cost, the profit with the rise of technology innovation will be decreasing in the beginning and increasing in the end. This relationship between fixed cost and profit can also be read in [35] by Png. And we simply conduct several groups of numerical experiments to confirm this point of view.

Proposition 4. Impact of technology advancement $\alpha$ on demand (sales):

(1) For the demand in the former period, $\partial Q_{1} / \partial \alpha<0$, and for the demand in the latter stage, $\partial Q_{2} / \partial \alpha>0$. And the total demand can be increasing or decreasing in $\alpha: \partial Q / \partial \alpha>0$ when $\theta<2(1-\delta) / \delta$, and $\partial Q / \partial \alpha \leq 0$ otherwise.

(2) The demand of both myopic and strategic consumers can be increasing or decreasing in $\alpha: \partial Q^{m} / \partial \alpha>0$ and $\partial Q^{s} / \partial \alpha>$ 0 when $\theta<2(1-\delta) / \delta$, or $\partial Q^{m} / \partial \alpha \leq 0$ and $\partial Q^{s} / \partial \alpha \leq 0$ otherwise.

It is easy to understand the shifts where consumers tend to decrease the purchase in the first period and increase the purchase in the second period, because of the optimal pricing strategy, which has been the finding in Proposition 4, in addition to the total demand bias under the different constituent of consumers (as shown in Figure 3), which is similar to the findings in Proposition 4. That is, when there is greater proportion of strategic consumers in the 


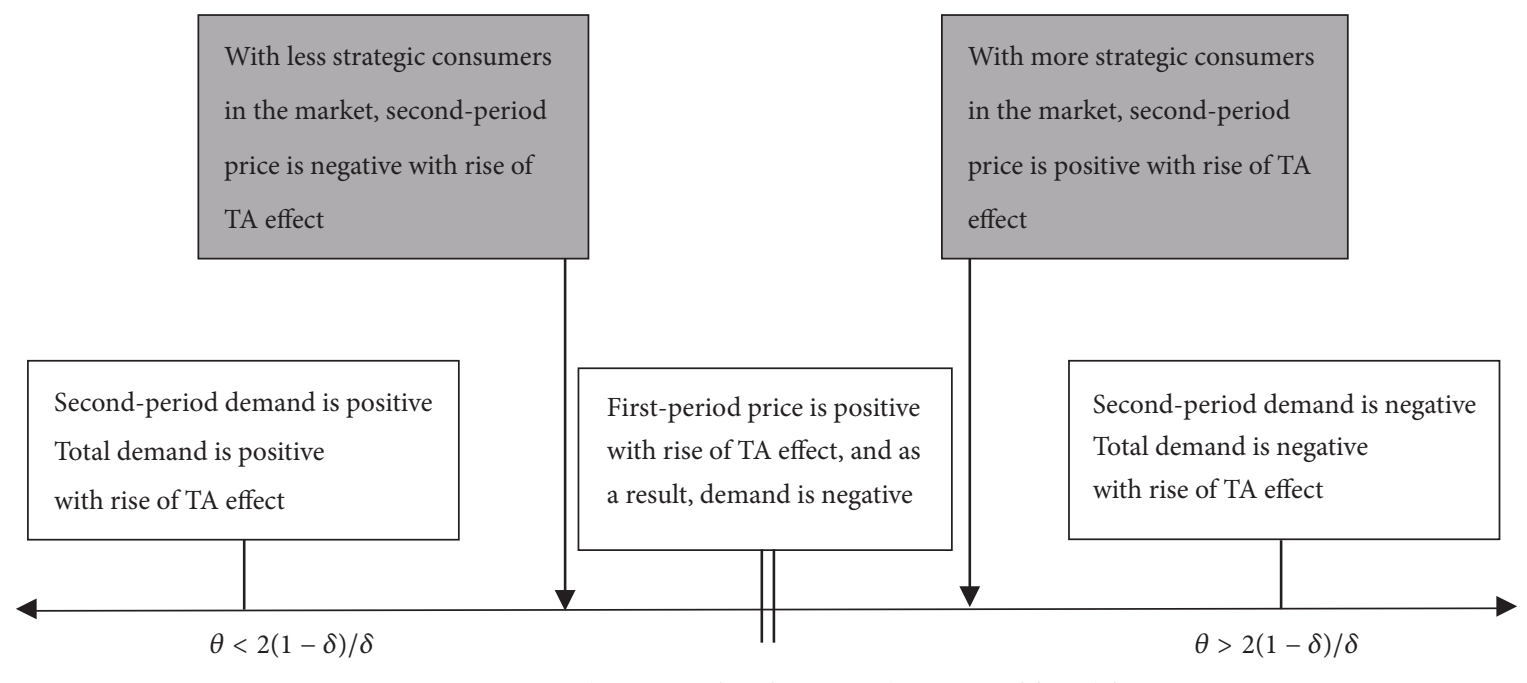

Figure 3: Moderation effect from combination of $\theta$ and $\delta$.

market, the total sales will decrease and increase otherwise. More consumers choose to wait. This is especially true when the technology advancement effect is significant. Thus, in this situation, a large demand will be transferred to next period. Then the pricing strategy in the second period matters; as a result, the total demand of product will increase in $\alpha$ when $\theta<2(1-\delta) / \delta$ and decrease otherwise.

If we divide the demand depending on different consumer segments, the other observation is that both myopic and strategic demand will increase in $\alpha$ when $\theta<2(1-$ $\delta) / \delta$ and decrease otherwise. On the one hand, for myopic consumers, it is the decrease of the second-period price that contributes to the rise of total demand of myopic consumers when facing the lower proportion of strategic consumers (price shifts have been proved in Proposition 3). On the other hand, for strategic consumers, the demand will increase because of the lower price in second period without customer constituent change. In conclusion, customer constituent has a moderation impact on the relationship between technology advancement effect and both myopic and strategic demand. This meaningful finding reminds the company that the constituent analysis and patience investigation of consumers are necessary before operating a technology advancement task.

4.2. Impact of Strategic Consumer Proportion. After recognition of cost reduction impact, now we turn to the influence of strategic consumer proportion. This ratio, which reflects the constituent of consumers in targeted market, turns out to be very important for policy makers especially when facing forward-looking customers. The influence is directly exerted on pricing and sales policies and, as a result, on optimal profit. In this section, we provide some insights into optimal solutions when considering the impact of strategic consumer proportion. In particular, we first consider the impact on expected sales in Proposition 5.

Proposition 5. Impact of the proportion of strategic consumers $\theta$ on demand (sales):
(1) The demand for the first stage $Q_{1}^{*}$ is decreasing in $\theta$, but the demand for the second stage $Q_{2}^{*}$ is increasing in $\theta$. Anyway, the total demand $Q_{1}^{*}+Q_{2}^{*}$ will be decreasing in $\theta$.

(2) The difference between two-stage demand $Q_{2}^{*}-Q_{1}^{*}>0$ if and only if $\mathrm{c}<\theta(2-\delta) /(\delta \theta+2-2 \delta)$, and $\partial\left(Q_{2}^{*}-Q_{1}^{*}\right) / \partial \theta>0$.

(3) If divided by consumer segmentation, $\partial Q^{m} / \partial \theta<0$ and $\partial Q^{s} / \partial \theta>0$.

Figure 4 illustrates how proportion of strategic consumers influences the demand, when $\delta=0.7, c=0.5$. Note that cost reduction from technology used to have a relatively low extent of impact on cost reduction, and we set $\alpha=0.01$. From Figure 4(a), with increase in $\theta$, the demand for the first period decreases, but the one for second period increases. We can also find that the total demand decreases, and the difference between two stages becomes larger.

From Figure 4(b), with the increase in $\theta$, the total demand of strategic customers increases and demand of myopic customers decreases. However, the total demand will increase.

If we divide the total sales by different purchasing stages, it is better for the firm to sell less products in the first period and more in the second period, with increase of strategic consumers proportion. With significant technology advancement effect, consumers will have a strong incentive to wait. Also, the rise in the proportion of strategic consumers may lead to more consideration of the trade-off between two purchasing stages. The company should provide a significant cutoff on the first-period price to weaken the incentive, which may contribute a bigger profit loss than that when just letting them delay the purchase. In addition, the firm may prefer more customers to wait because the significant technology advancement effect raises up the profit margin of product in the latter period.

The total demand decreases, which can be interpreted by the fact that the increase in the second-period demand cannot make up the fall in the first-period demand. This can be proved by the difference between two period sales $Q_{2}^{*}-Q_{1}^{*}$ decreasing in $\theta$. When facing the cost reduction, 


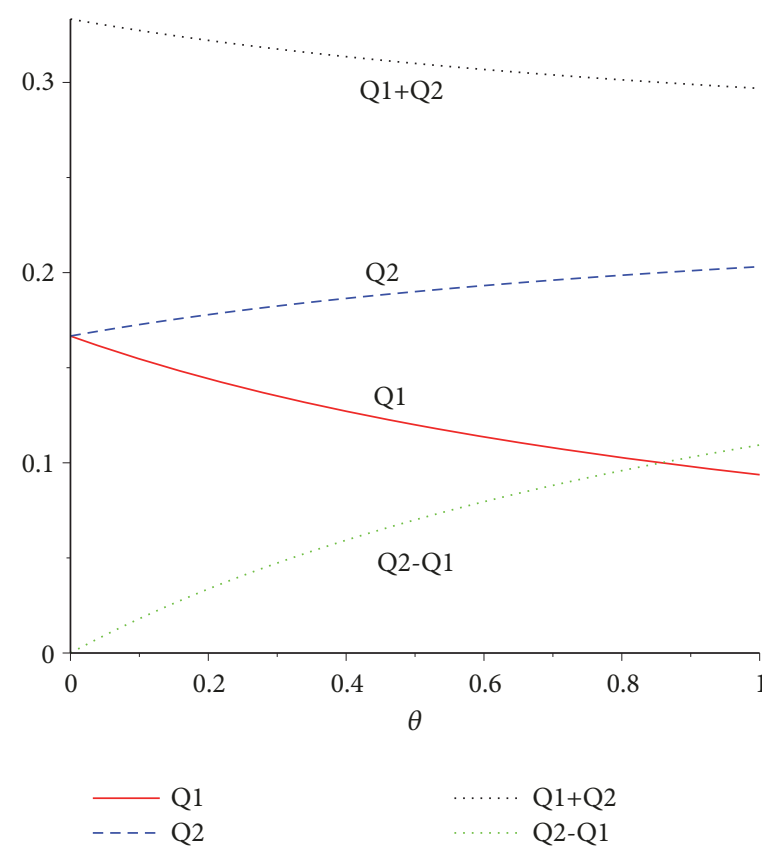

(a) By different purchasing stages

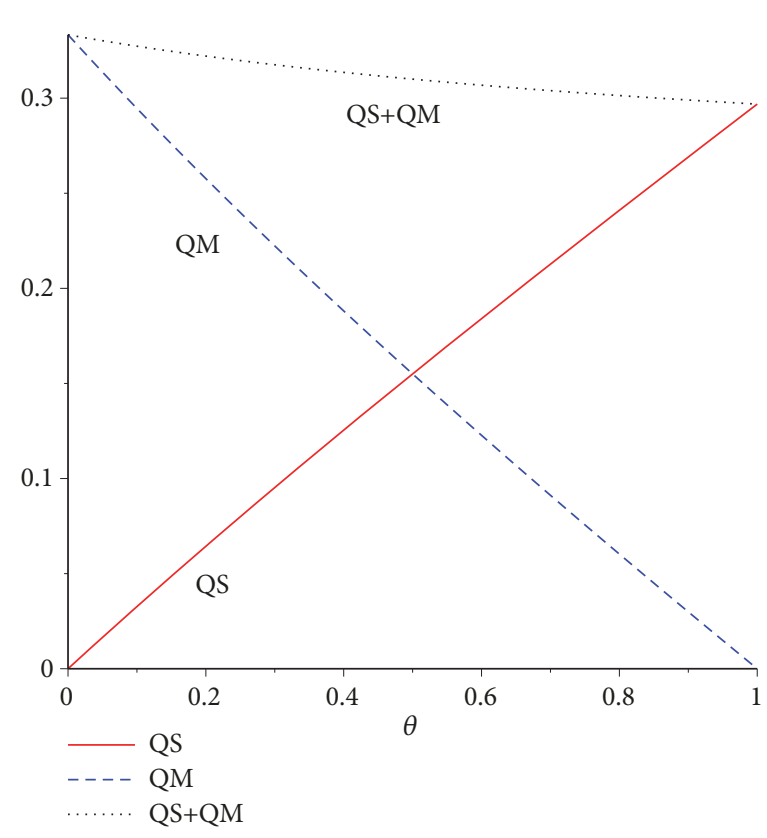

(b) By different customers segments

Figure 4: Impact of the proportion of strategic consumer $\theta$ on demand (sales).

more strategic consumers would delay their purchase as we discuss above and part of them will give up their purchase. The former choice will transfer the demand from first period to second; however the latter situation contributes to loss of customers. On the one hand, the strategic consumers whose valuation $v_{s}<\bar{v}$ (according to Lemma 1.) would have made purchase decision in the first period, but the message of cost reduction may mislead them, which induces more consumers to wait until the second period. On the other hand, the firm will increase the price in the second period to improve the profit. The strategic consumers lose the product availability and purchasing opportunities in the first period. In this situation, especially the strategic consumers will lose the freedom of when to buy and only have the choice of whether or not to buy. Besides raising up the second-period price, firm can decrease the first-period price to improve profit, which will be further discussed next.

Additionally, if we divide the total sales depending on different consumer segments, the sales from myopic consumers will decline sharply and the sales from strategic consumers will rise. This is mainly because the proportion of strategic consumers increases. As a result, the firm should pay more attention to and make specific strategies targeting the strategic consumers.

Similarly, we have also conducted the robustness analysis on the impact of the proportion of strategic consumers $\theta$ on firm's pricing and expected profit:

(1) $p_{1}^{*}$ is decreasing in $\theta$ and $p_{2}^{*}$ is increasing in $\theta$. However, the reduction range $p_{1}^{*}-p_{2}^{*}$ decreases in $\theta$.

(2) The expected profit for the first period is decreasing in $\theta$, and the expected profit for the second period is increasing in $\theta$. However, the total profit of company $\pi_{2 s}^{*}$ is decreasing in $\theta$.
As we have mentioned above, the increase in proportion of strategic consumers means more strategic consumers such that they will consider their surplus from purchasing the product and make a trade-off between two stages to maximize their surplus. This may worry the firm in that the sales in the first period where the marginal profit is relatively higher will drop, which motivates the firm to reduce the first-period price to retain more consumers making purchase decision in the former stage and weaken the trend of transferring demand to second period. On the contrary, the company may have motivation to attract strategic consumers to the second period. In the second period, the strategic consumers only have the purchase decision of whether to buy, and lose the freedom of timing their purchase stages. As a result, the firm may raise up the selling price to maximize their profit. What is more, the difference between the prices in two stages will decrease with the rise of strategic consumers. This is easy to explain because of the opposite shift directions of two-stage prices.

Actually, we get the conclusion that the first-period price should descend with more strategic consumers in the market. It really concerns us that there is still some motivation behind raising the price in the former stage, that is, the influence of cost reduction. With massive selling quantity, each dollar of cost reduction would make the seller more rubricate. This may indicate that more demand, especially strategic demand, met in the second period benefits the seller where higher marginal profit happens with the significant technology advancement. This counterintuitive finding can also be read in the studies by Kremer [25] and Shum et al. [5].

Furthermore, the expected profit will go up in the first period and go down in the second period. This keeps pace 
with the change of price which is lower in the beginning and higher in the end. In addition to the reason of price, we cannot ignore the shifts in sales. More strategic consumers choose to delay the purchase until the second period. These two reasons explain why the expected profit is up sooner but down later. Moreover, the total profit will decrease when facing more forward-looking consumers in the market. On the one hand, the total sales quantity decreases, which can be found in Proposition 5 (1). On the other hand, the firm should increase the first-period price and decrease the second-period price, which makes it hard for us to tell whether the average profit will decrease or not. However, the potential motivation we talked about above may help explain the decrease of the total profit.

4.3. Impact of Customer Patience. Customer patience, in a way, can be viewed as waiting cost, according to $\mathrm{Su}$ [9]. This usually measures the extent of willingness to wait, for strategic consumers. In addition to the quantitative effect of strategic consumer proportion, it is another dimension to study the characteristic of market. We provide insights into the optimal solution for operational policies makers particularly when facing heterogeneous strategic consumers. This part focuses on the surprising impact of customer patience, as a property belonging to strategic consumers, on myopic demand in Proposition 6. Moreover, we cast light on the relationship between strategic consumer proportion and customer patience in Proposition 7, especially when maximizing the expected profit. The numerical study also examines the robustness of both these parameters.

Sharing the similarity with the robustness analysis of strategic consumers proportion, we also perform the analysis of customer patience. First, the analysis suggests the following:

(1) The demand for the first stage $Q_{1}^{*}$ is decreasing in $\delta$, but the demand for the second stage $Q_{2}^{*}$ is increasing in $\delta$. Anyway, the total demand $Q_{1}^{*}+Q_{2}^{*}$ will be decreasing in $\delta$.

(2) The difference between two-stage demand $Q_{2}^{*}-Q_{1}^{*}>0$ if and only if $c<\theta(2-\delta) /(\delta \theta+2-2 \delta)$, and $\partial\left(Q_{2}^{*}-Q_{1}^{*}\right) / \partial \delta>0$.

In addition, we conduct the analysis of customer patience $\delta$ on firm's pricing and expected profit:

(1) Let $p_{1}^{*}$ and $p_{2}^{*}$ be the equilibrium prices. Then $p_{1}^{*}$ is decreasing in $\delta$ and $p_{2}^{*}$ is increasing in $\delta$. However, the reduction range $p_{1}^{*}-p_{2}^{*}$ decreases in $\delta$.

(2) The expected profit for the first period is decreasing in $\delta$, and the expected profit for the second period is increasing in $\delta$. However, the total profit of company $\pi_{2 s}^{*}$ is decreasing in $\delta$.

These results share so much similarity with the analysis for strategic consumers proportion, and that can be explained by the negative effect of strategic properties. However, according to our analysis, there also exist some counterintuitive findings of customer patience, which is relatively different from strategic proportion. And these findings will be shown in Proposition 6.

Proposition 6. With the increase of customer patience $\delta$, not only strategic but also myopic consumers will buy less $\left(\partial Q^{m} /\right.$ $\left.\partial \delta<0, \partial Q^{s} / \partial \delta<0\right)$.
We describe proportion of strategic consumers as parameter $\theta$ and individual strategic property as parameter $\delta$. When individual consumers are more patient, $\delta$ is larger. Apparently, the purchase decisions of individuals are independent and there exist no interference between myopic and strategic consumers. If we derive the analysis just within the consumer group, the conclusion is kind of counterintuitive. Nevertheless, if we include the reaction of a monopolistic seller, the result becomes easier to realize. We use $b, \delta, p$ to express "buy or not", "consumer patience", and "pricing strategies"; and the actions nearly happening at the same time are described as follows:

(i) In the beginning, myopic consumers only have the buy-or-not decision, denoted as $M(b)$. And the strategic consumers have one more characteristic parameter, consumer patience $\delta$, denoted as $S(b, \delta)$.

(ii) The seller who has one variable (denoted as $F(p)$ ) realizes the change and chooses to lower first-period price and raise the second-period price.

(iii) Both myopic and strategic consumers decrease the demand of purchase.

The pricing strategies during rise of consumer patience have been proved in Appendix A. In a nutshell, increase of customer patience $\delta$ will contribute less demand of not only strategic but also myopic consumers.

Proposition 7. When $\theta>2.768 \delta^{2}-6.1046 \delta+3.3512$, there exists a profit diversion, and there is no profit diversion otherwise.

When there is a cost reduction $\alpha=0.01$, we try different valuation of proportion of strategic consumers as in Figure 5, and from above expected profit in first period always decreases and expected profit in second period increases. As a result, the total profit $\pi_{2 s}^{*}$ is decreasing. Further, we can clearly find the moderating effect of customer patience, which enables the expected profit steeper under a higher valuation of customer patience. And the relationship between proportion of strategic consumers and pricing strategies has been conducted in Proposition 7.

Another observation is that when there exists a relatively high customer patience, the profit diversion occurs. This diversion can be easily found in Figure 5 after comparison between different combinations of $\theta$ and $\delta$. A similar revenue diversion finding can be read in the study by Kremer [25], where he performs a behavioral experiment. In that experiment, when he gives the proportion of strategic consumers of 0.5 , he finds theoretically that most of the expected revenue has been diverted into the second season. Nevertheless, in our findings, the proportion of strategic consumers is just one of the properties of the whole consumer group that contribute to the revenue diversion. In our research,we give two dimensions to depict that, which are proportion of strategic consumers and customer patience. By controlling different combination of $\theta$ and $\delta$, the profit diversion will be more significant when $\theta$ and $\delta$ are higher in the combination.

To prove this, we derive a numerical study as shown in Table 2 . 
TABLE 2: Expected minimum profit under different unit cost of TA.

\begin{tabular}{|c|c|c|c|c|c|c|c|c|c|c|c|}
\hline & \multicolumn{11}{|c|}{ range } \\
\hline$\delta$ & 0.01 & 0.1 & 0.2 & 0.3 & 0.4 & 0.5 & 0.6 & 0.7 & 0.8 & 0.9 & 0.99 \\
\hline$\theta$ & NA & NA & NA & NA & NA & 1 & 0.67 & 0.43 & 0.25 & 0.11 & 0.01 \\
\hline & \multicolumn{11}{|c|}{ range } \\
\hline$\delta$ & 0.99 & 0.91 & 0.83 & 0.77 & 0.71 & 0.67 & 0.63 & 0.59 & 0.56 & 0.53 & 0.5 \\
\hline$\theta$ & 0.01 & 0.1 & 0.2 & 0.3 & 0.4 & 0.5 & 0.6 & 0.7 & 0.8 & 0.9 & 0.99 \\
\hline
\end{tabular}

NA: out of range $(0,1)$.

Numbers in italics: values approaching boundary.

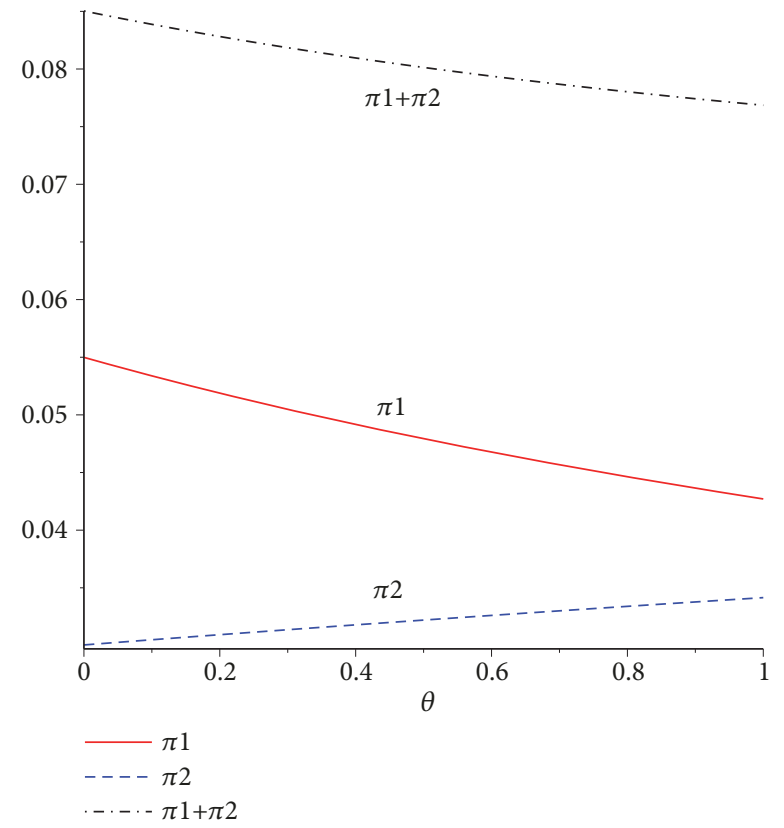

(a) Relationship when $\delta=0.3, c=0.5$

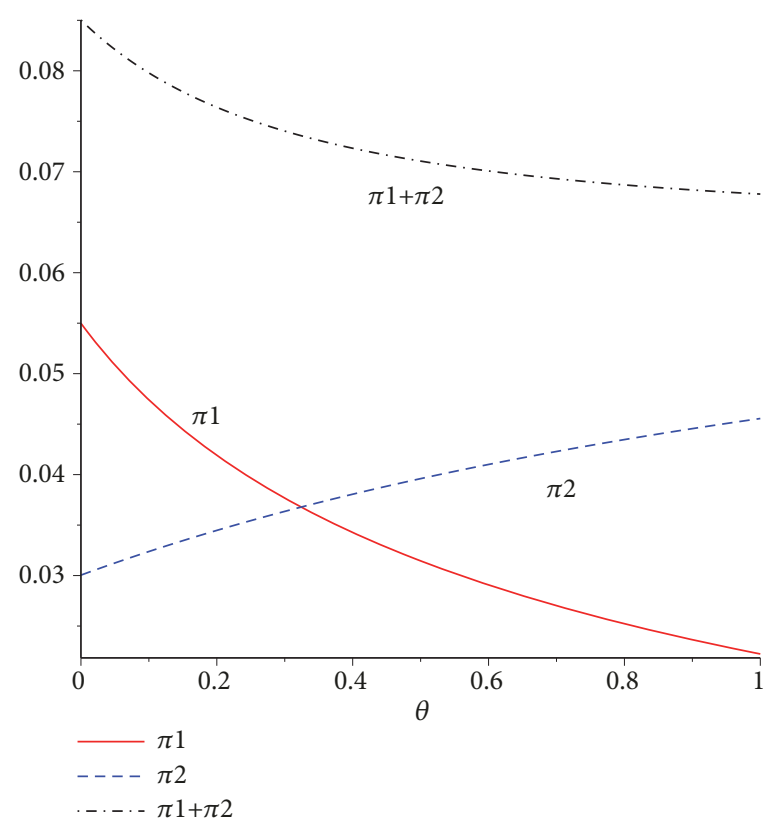

(b) Relationship when $\delta=0.7, c=0.5$

FIGURE 5: Relationship between proportion of strategic consumers $\theta$ and seller's expected profit.

We choose $\theta$ from 0 by 0.1 to 1 , where we use 0.01 to replace 0 and use 0.99 to replace 1 ; and we choose $\delta$ the same as that of $\theta$. Further, we derive the solution of the appearance point of revenue diversion, listed in Table 2. As a result, we depict a fitting curve to approach the successive condition. We got fitting equation of $\theta=2.768 \delta^{2}-6.1046 \delta+3.3512$ with test of agreement $R^{2}=0.9993$. The fitting curve has been shown in Figure 6.

According to our finding, there exists revenue diversion $\left(\pi_{1}<\pi_{2}\right)$ when customer patience and proportion of strategic consumers have relatively high value. This means when there are more strategic consumers in the market or the extent of consumers is more strategic, the seller's profit will shift to the second period. Furthermore, this finding indicates that the seller should pay more attention to the second period including pricing and sales strategies. Additionally, research like sampling is necessary to protest the consumer properties, particularly proportion of strategic consumers and customer patience. And when profit diversion happens, out of the flexibility of dynamic pricing, the seller may be lucrative than in other pricing strategies, like price commitment and price matching.
Another observation is that consumer patience has more robustness than proportion of strategic consumers, which is easy to see in Figure 6. Further, according to our research, revenue diversion will not happen as far as the value of customer patience is under 0.5. In other words, customer patience may be more influencing than proportion of strategic consumers.

Corollary 8. The pricing and sales strategy will differ under different combination of consumer constituent and consumer patience. Particularly, in our analysis, the indifferent condition can be expressed as $\theta=2(1-\delta) / \delta$.

Once facing cost reduction, maybe resulting from $\mathrm{TA}$, the ordinary decision for the firm is to decrease the price and attract more demand and, as a result, reach a new equilibrium where the total profit will increase. However, our research gets new findings, contrary to conventional wisdom, which motivate researchers to consider the properties of consumer group. From our research, we consider the properties from two dimensions, proportion of strategic consumers $\theta$ and consumer patience $\delta$, to picture consumers. That is, under different combination of proportion and consumer patience, 


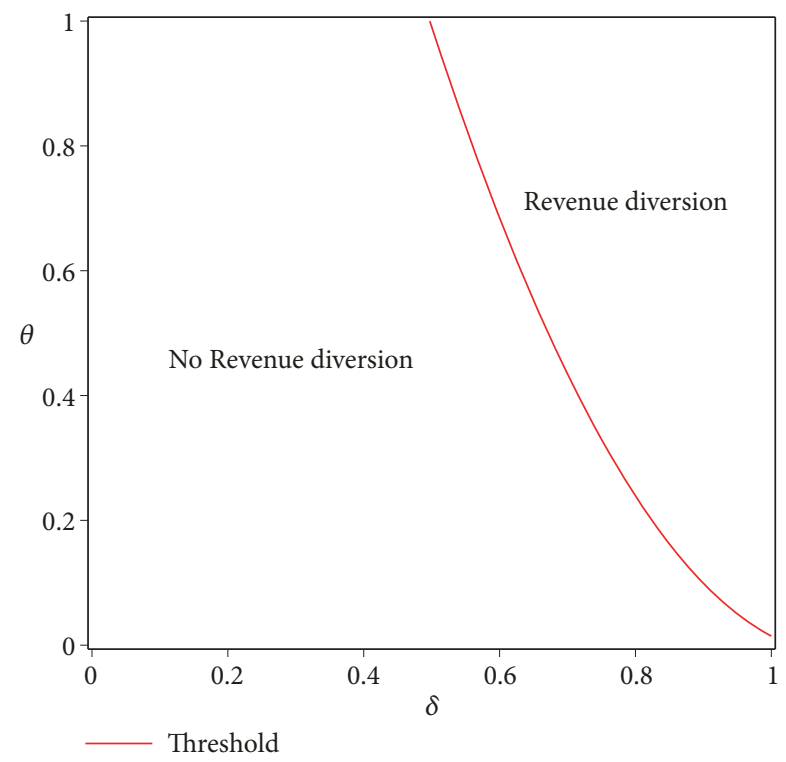

FIGURE 6: Conditional existence of revenue diversion.

the pricing and sales strategy differ with the change of TA extent, especially in the second period. This requires sellers to pretest and analyze the population properties before making strategic decisions. Similar counterfactual findings of different impacts from different market structures were also reported by Li et al. [4]. In the research of air-travel industry, they give some valuable conclusions that different pricing strategies should be implemented in different markets, like leisure market and business market, to maximize profit.

\section{Conclusion}

Cost reduction induces the company to adjust its pricing strategies to accommodate the demand shifts in the market of both strategic and myopic consumers. Under cost reduction resulting from technology advancement, we investigate the impact from strategic behavior. We find that both proportion of strategic consumers and consumer patience will contribute to a more strategic identity of consumers collectively and individually. This means when consumers, especially strategic ones, face cost reduction, they tend to delay their purchase and wait until the second period. Thus, the seller will react to decrease the first-period price to weaken this trend. And the second-period pricing strategy is easy to realize with a rise to slow down this shift. However, another incentive for seller to increase the second-period price is to raise profit. This can be depicted as "rob the owner while his house is on fire". In this situation, especially the strategic consumers who lose the freedom of when to buy only have the choice of whether to buy. Furthermore, when facing great enough proportion of strategic consumers (or customer patience), profit diversion will happen, which means the profit from the latter period exceeds the one from the first period. Under profit diversion, dynamic pricing strategy enable the seller to squeeze more consumer surplus in the second period because it decreases the uncertainty when strategic consumers are going to purchase.
In addition, with the increase of customer patience, not only strategic but also myopic consumers will buy less. This counterintuitive finding can also result from the mediation effect of pricing strategy. In case of serious strategic waiting, the firm chooses to decrease the markdown on second-period price, which contributes to the reduction of both strategic and myopic total demand.

Other than that, we also investigate the impact of cost reduction as an endogenous variable. In this paper we assume that cost reduction arises out of TA; however, Jin [30] and Hatch [36] investigate the production learning effect and also take it as an important factor in cost reduction. In our research, surprisingly there exists a threshold as a combination of proportion of strategic consumers and consumer patience. When proportion of strategic consumers exceeds a threshold, the seller will provide a higher secondperiod price when facing the cost reduction, and a lower one otherwise. This conclusion on pricing also accounts for the counterintuitive findings in demand. These discoveries above are declared in models for the first time, yet former researches have been a notable success in dynamic pricing. Shum [5] compared three different pricing strategies, which are dynamic pricing, price commitment, and price matching. There are also empirical studies that may support our conclusion, like that of Li [4]. From Li's study about the total strategic property of consumers in a certain market, it was indicated that under different strategic extent, the estimation of proportion of strategic consumers differs. Thus, it is necessary for the company to figure out the constituent and consumer patience before making the second-period pricing strategy. Maybe it is feasible to make sampling survey or conduct data analysis of the consumers' relative shopping tracks.

Our study also has limitations which, in turn, are opportunities for future researches. First, we have not taken expenses of TA into consideration, which are usually a fixed cost. This may lack the analysis of the shut-down point of TA, which means TA strategy should be abandoned when it is too costly. The lack contributes to the conclusion that seller needs as much TA as possible, which is counterfactual. In addition, we just study the reaction of buyer and seller under single pricing strategy; besides there are still price commitment and price matching strategies in ordinary studies among revenue management. Those strategies have been studied by Aviv [11] and Su [37]. Furthermore, future studies could not only study the cost reduction under dynamic pricing but also make the comparison among three pricing strategies. Finally, the situation may be more complicated when facing both intertemporal pricing strategies and competitions among sellers. Multiple researchers have paid attention to that, like Liu [12] in rationing risk and Su [37] in supply chain performance.

\section{Appendix}

\section{A. Proofs}

Proof of Lemma 1. The utility of a strategic consumer is $v-p_{1}$ in the first period and $\delta\left(v-p_{2}\right)$ in second period. There 
exists a critical valuation $\bar{v}$, which contributes to $\bar{v}-p_{1}=$ $\delta\left(\bar{v}-p_{2}\right)$. That is, $\bar{v}=\left(p_{1}-\delta p_{2}\right) /(1-\delta)$. Also we set the valuations of strategic consumers to be distributed uniformly on the interval $[0,1]$. As a result, the critical valuation is $\bar{v}=\min \left\{1,\left(p_{1}-\delta p_{2}\right) /(1-\delta)\right\}$. Note that whenever $\bar{v}=1$ $\left(\left(p_{1}-\delta p_{2}\right) /(1-\delta) \geq 1\right)$, the strategic consumers will not buy in early season because of $v \leq \bar{v}$ all the time.

Proof of Proposition 2. According to Lemma 1, $\bar{v} \leq 1$, which equals $v_{E}<1$, guarantees the strategic consumers will purchase in both periods. And in this part, we solve this dynamic pricing problem backward and get the objective function-(7). Then we make a second derivative of the twoperiod profit, $\pi_{2 s}^{\prime \prime}\left(p_{1}\right)=2\left(t^{2}-2 t\right)$, where $t=(\delta \theta+(1-\delta)) /(\delta \theta+$ $2(1-\delta)) \in(0,1)$, and as a result, $\pi_{2 s}^{\prime \prime}\left(p_{1}\right)<0$, which means $\pi_{2 s}$ is concave in $p_{1}$. We derive the first-order condition and get the optimal pricing in the first period

$$
p_{1}^{*}=\frac{N_{1} \alpha+N_{2} c+N_{3}}{2(\delta \theta-\delta+1)(\delta \theta-3 \delta+3)}
$$

Here $N_{1}=\delta^{2} \theta^{2}-2 \delta^{2} \theta+2 \delta^{2}+2 \delta \theta-4 \delta+2, N_{2}=\delta^{2} \theta^{2}-4 \delta^{2} \theta+$ $2 \delta^{2}+4 \delta \theta-4 \delta+2$, and $N_{3}=\delta^{2} \theta^{2}-4 \delta^{2} \theta+4 \delta^{2}+4 \delta \theta-8 \delta+4$.

And by the equilibrium $\bar{v}-p_{1}=\delta\left(\bar{v}-p_{2}\right)$, we can get the second-period optimal pricing

$$
p_{2}^{*}=\frac{N_{4} \alpha+N_{5} c+\theta \delta-2 \delta+2}{2(\theta \delta-3 \delta+3)}
$$

where $N_{4}=\theta \delta+2 \delta-2$ and $N_{5}=\theta \delta-4 \delta+4$.

Also, we can make substitution of $p_{1}^{*}$ to get the total expected profit

$$
\pi_{2 s}^{*}=\frac{\left.c^{2}(\delta \theta-2 \delta+2)^{2}+c\left(2 \delta^{2} \theta^{2}+(\delta+2) M_{1}\right)+\left(\alpha^{2} M_{2}+(\alpha+1) M_{3}-\delta^{2} \theta^{2}\right)\right)}{4(\delta \theta-3 \delta+3)(\delta \theta-\delta+1)}
$$

where $M_{1}=-2 \delta^{2} \theta^{2}+4 \delta^{2} \theta-4 \delta \theta-4 \delta^{2}+8 \delta-4, M_{2}=$ $5 \delta^{2} \theta^{2}-8 \delta^{2} \theta+4 \delta^{2}+8 \theta \delta-8 \delta+4$, and $M_{3}=2 \delta^{2} \theta^{2}-4 \delta^{2} \theta+$ $4 \delta^{2}+4 \theta \delta-8 \delta+4$.

According to Lemma $1, \bar{v}=1$, which equals $v_{E} \geq 1$, guarantees that there is no strategic consumer purchase in the former period. And the objective function can be expressed as follows.

$$
\begin{aligned}
\pi_{1 s}^{*}\left(p_{1}, p_{2}\right) & \\
= & (1-\theta)\left(1-p_{1}\right)\left(p_{1}-c\right) \\
& +(1-\theta)\left(p_{1}-p_{2}\right)\left(p_{2}-c_{2}\right) \\
& +\theta\left(1-p_{2}\right)\left(p_{2}-c_{2}\right)
\end{aligned}
$$

$$
\text { s.t. } \frac{[2-\delta(1-\theta)] p_{1}-\delta(c-\alpha)}{2(1-\delta)+\delta \theta} \geq 1
$$

Then we make a second derivative of the two-period profit, where $\pi_{1 s}^{\prime \prime}\left(p_{1}\right)=2(\theta-1)$ and $\pi_{1 s}^{\prime \prime}\left(p_{2}\right)=-2$. This result indicates $\pi_{1 s}$ is concave in both $p_{1}$ and $p_{2}$. We derive the firstorder condition and get the optimal pricing in the first period, $p_{1}^{*}=(c+\theta+\alpha+2) /(\theta+3), p_{2}^{*}=(2 c+(1+\theta)(1-\alpha)) /(\theta+3)$.

Under these pricing policies, the seller's expected maximum profit can be formed as $\pi_{1 s}^{*}=\left(\alpha^{2}+(1-c)^{2}+(1+\theta)(1-\right.$ c)) $/(\theta+3)$.

The firm's objective is to maximize the overall profit.

$$
\begin{aligned}
\max _{p_{1}} & \pi=\frac{\left(c-p_{1}\right)\left(\delta \theta\left(\alpha-c+2 p_{1}-1\right)-2 \delta p_{1}+2 \delta+2 p_{1}-2\right)}{\theta \delta-2 \delta+2}+\frac{(\theta \delta-\delta+1)^{2}\left(\alpha-c+p_{1}\right)^{2}}{(\theta \delta-2 \delta+2)^{2}} \\
\text { s.t. } & \frac{[2-\delta(1-\theta)] p_{1}-\delta(c-\alpha)}{2(1-\delta)+\delta \theta}<1
\end{aligned}
$$

Note that $\pi$ is concave in $p_{1}$. Using first-order condition, we can get $p_{1}^{*}=\left(N_{1} \alpha+N_{2} c+N_{3}\right) /(2(\delta \theta-\delta+1)(\delta \theta-3 \delta+3))$, where $N_{1}=\delta^{2} \theta^{2}-2 \delta^{2} \theta+2 \delta^{2}+2 \delta \theta-4 \delta+2, N_{2}=\delta^{2} \theta^{2}-4 \delta^{2} \theta+$ $2 \delta^{2}+4 \delta \theta-4 \delta+2$, and $N_{3}=\delta^{2} \theta^{2}-4 \delta^{2} \theta+4 \delta^{2}+4 \delta \theta-8 \delta+4$.

The condition $\left([2-\delta(1-\theta)] p_{1}-\delta(c-\alpha)\right) /(2(1-\delta)+\delta \theta)<1$ can be expressed as

$\alpha /(1-c)<\left(\delta^{2} \theta^{2}+\delta^{2} \theta-2 \delta^{2}+2 \delta \theta+2\right) /\left(\delta^{2} \theta^{2}-5 \delta^{2} \theta+\right.$ $\left.4 \delta^{2}+4 \delta \theta-6 \delta+2\right)$. Therefore, when $\alpha /(1-c) \geq\left(\delta^{2} \theta^{2}+\delta^{2} \theta-\right.$ $\left.2 \delta^{2}+2 \delta \theta+2\right) /\left(\delta^{2} \theta^{2}-5 \delta^{2} \theta+4 \delta^{2}+4 \delta \theta-6 \delta+2\right)$, the strategic demand only happens in the second period; when $\alpha /(1-c)<$ $\left(\delta^{2} \theta^{2}+\delta^{2} \theta-2 \delta^{2}+2 \delta \theta+2\right) /\left(\delta^{2} \theta^{2}-5 \delta^{2} \theta+4 \delta^{2}+4 \delta \theta-6 \delta+2\right)$, the strategic demand happens in both periods.
Proof of Proposition 3. Impact of technology advancement $\alpha$ on price and expected profit:

(a) $(\partial / \partial \alpha) p_{1}^{*}=\left(\delta^{2} \theta^{2}+2 \theta \delta(1-\delta)+2(\delta-1)^{2}\right) / 2(\delta \theta-3 \delta+$ 3) $(\delta \theta-\delta+1)$, which is positive.

(b) $(\partial / \partial \alpha) p_{2}^{*}=(\delta \theta+2 \delta-2) / 2(\delta \theta-3 \delta+3)$, which is positive if and only if $\theta>2(1-\delta) / \delta$.

(c) $(\partial / \partial \alpha) \pi^{*}=\left(\alpha\left(5 \delta^{2} \theta^{2}+8 \theta \delta(1-\delta)+4(\delta-1)^{2}\right)+(1-\right.$ $\left.c)\left(\delta^{2} \theta^{2}+2 \theta \delta(1-\delta)+2(\delta-1)^{2}\right)\right) /(\delta \theta-3 \delta+3)^{2}(\delta \theta-\delta+1)$, which is positive.

Proof of Proposition 4. Impact of technology advancement $\alpha$ on demand: 
After calculating the demand, price, and profit in two stages, we start to analyze the influence of technology advancement.

We derive sensitivity analysis results as follows:

(a) $(\partial / \partial \alpha)\left(Q_{1}^{*}+Q_{2}^{*}\right)=-(\delta \theta+2 \delta-2) / 2(\delta \theta-3 \delta+3)$, which is positive if and only if $\theta<2(1-\delta) / \delta$.

(b) $(\partial / \partial \alpha)\left(Q_{1}^{*}-Q_{2}^{*}\right)=(7 \delta \theta-6 \delta+6) / 2(\delta \theta-3 \delta+3)$, which is positive.

(c) $(\partial / \partial \alpha) Q^{s}=-\theta(\delta \theta+2 \delta-2) / 2(\delta \theta-3 \delta+3)$, which is positive if and only if $\theta<2(1-\delta) / \delta$.

(d) $(\partial / \partial \alpha) Q^{m}=(\theta-1)(\delta \theta+2 \delta-2) / 2(\delta \theta-3 \delta+3)$, which is positive if and only if $\theta<2(1-\delta) / \delta$.

Proof of Proposition 5. The demand of consumers is $Q_{1}^{*}=(1-$ $\delta)(1-c) /(\delta \theta-3 \delta+3)$ in former period and $Q_{2}^{*}=(\delta \theta-2 \delta+$ $2)(1-c) / 2(\delta \theta-3 \delta+3)$ in the latter period. The difference between two-stage demand $Q_{1}^{*}-Q_{2}^{*}=((\delta \theta-2 \delta+2) c+$ $\delta \theta-2 \theta) /(\delta \theta-3 \delta+3)$, which is positive if and only if $c<$ $\theta(2-\delta) /(\delta \theta+2-2 \delta)$.

And the demand of strategic consumer and the demand of myopic consumers are as follows.

$$
\begin{aligned}
Q^{s} & =\theta\left(1-p_{2}\right)=\frac{\theta(1-c)(\delta \theta-4 \delta+4)}{2(\delta \theta-3 \delta+3)}, \\
Q^{m} & =(1-\theta)\left(1-p_{2}\right) \\
& =\frac{(1-\theta)(1-c)(\delta \theta-4 \delta+4)}{2(\delta \theta-3 \delta+3)}
\end{aligned}
$$

Then we derive sensitivity analysis by acquiring first-order derivative, similar to proof of Proposition 4.

Proof of Proposition 6. Impact of customer patience $\delta$ on myopic and strategic demand:

(a) $(\partial / \partial \delta) Q^{m}=(c-1)(1-\theta) \theta / 2(\delta \theta-3 \delta+3)^{2}$, which is negative.

(b) $(\partial / \partial \delta) Q^{s}=(c-1) \theta^{2} / 2(\delta \theta-3 \delta+3)^{2}$, which is negative.

Then we derive sensitivity analysis by acquiring firstorder derivative, similar to proof of Proposition 4.

\section{B. Tables and Graphs}

Here, we present some tables and graphs to illustrate the unfinished discussion of Proposition 3 (2) once there exists the expense of technology advancement (used to be fixed cost).

The total profit in our study is always increasing with TA, and that is the result of not calculating the cost of TA. If we rederive the function of expected profit with the fixed cost of TA, we may get some different conclusion, as in Figure 7. The new function of total profit is $\pi^{\prime}=\pi-0.4 \alpha$, and we set $\theta=0.3$, $\delta=0.7$, and $c=0.5$, so that we can get the different trend of expected profit.

That is, the profit is not always increasing with TA when considering the innovation cost. Further, when unit cost is 0.4 for TA, we find the total profit will decrease in the beginning and increase in the end. The min point is about $\left(0.256, \pi_{\min }\right)$. This indicates the TA does not fit "more is better".

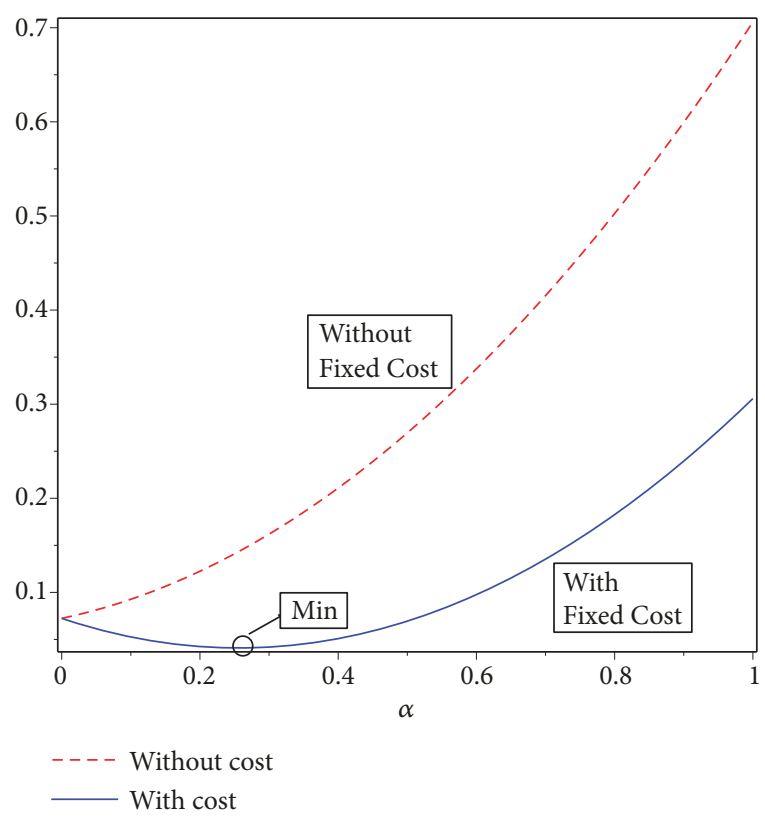

FIGURE 7: The case when technology advancement is costly.

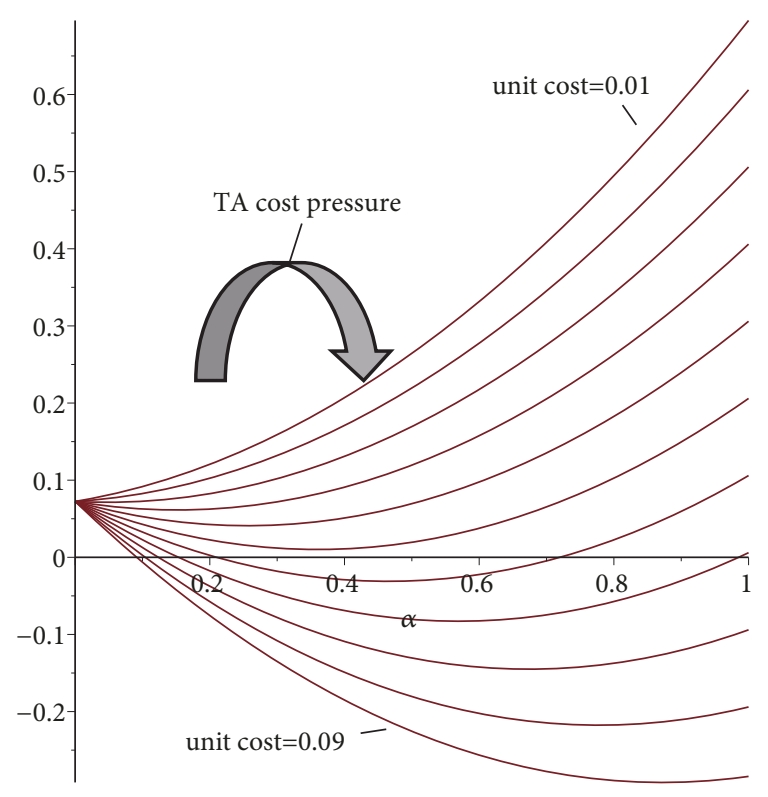

FIgURE 8: Expected profit under different TA cost pressure.

Then we derive different tests during ranges of unit cost by step length of 0.1 .

In Table 3, we calculate the minimum points and their values under different unit cost of TA. From which, we can find the minimum point will shift to right and the minimum profit will decrease even below the axis. We also depict the changing trend in Figure 8, from which there exists the power force, the profit curve being steeper and deeper. We call this force the TA cost pressure, which shows the TA may be a burden when it is too costly. 
TABle 3: Expected minimum profit under different unit cost of TA.

\begin{tabular}{lcccccc}
\hline & \multicolumn{5}{c}{ Unit cost for TA } \\
\hline & 0.01 & 0.1 & 0.2 & 0.3 & 0.4 & 0.5 \\
Minimum point $(\alpha)$ & 0 & 0 & 0.047 & 0.151 & 0.256 & 0.361 \\
Minimum value $(\pi)$ & 0.072 & 0.072 & 0.071 & 0.061 & 0.041 \\
\hline & 0.6 & 0.7 Unit cost for TA & 0.99 \\
\hline & 0.465 & 0.569 & 0.8 & 0.778 & 0.872 \\
Minimum point $(\alpha)$ & -0.031 & -0.083 & -0.145 & -0.218 & -0.292 \\
\hline
\end{tabular}

\section{Data Availability}

The data used to support the findings of this study are included within the article.

\section{Conflicts of Interest}

The authors declare that there are no conflicts of interest regarding the publication of this paper.

\section{Acknowledgments}

The authors thank the sponsor for this research from the National Natural Science Foundation of China [71572154].

\section{References}

[1] Joseph Carey Mate 20 Pro launch live - Huawei reveals huge P20 Pro rival. Express, https://www.express.co.uk/life-style/ science-technology/1032139/Huawei-Mate-20-Pro-launch-liveP20-Pro-rival-revealed-today, 2018.

[2] E. Auchard, Sijia Jiang Huawei aims to challenge Apple and Samsung on technology as well as price. Reuters, https://www.reuters.com/article/us-smartphone-huawei-tech/ huawei-aims-to-challenge-apple-and-samsung-on-technologyas-well-as-price-idUSKBN1CL1SQ, 2017.

[3] Y. Levin, J. McGiil, and M. Nediak, "Optimal dynamic pricing of perishable items by a monopolist facing strategic consumers," Production and Operations Management, vol. 19, no. 1, pp. 4060, 2010.

[4] J. Li, N. Granados, and S. Netessine, "Are consumers strategic? Structural estimation from the air-travel industry," Management Science, vol. 60, no. 9, pp. 2114-2137, 2014.

[5] S. Shum, S. Tong, and T. Xiao, "On the impact of uncertain cost reduction when selling to strategic customers," Management Science, vol. 63, no. 3, pp. 843-860, 2017.

[6] Zhang Jiaran Huawei has spent nearly 400 billion yuan on R\&D in the past ten years and 100 billion yuan this year. The Paper, https://www.thepaper.cn/newsDetail_forward_2612249, 2018.

[7] G. Gallego and G. Van Ryzin, "A multiproduct dynamic pricing problem and its applications to network yield management," Operations Research, vol. 45, no. 1, pp. 24-41, 1997.

[8] D. Besanko and W. L. Winston, "Optimal price skimming by a monopolist facing rational consumers," Management Science, vol. 36, no. 5, pp. 555-567, 1990.

[9] X. Su, "Intertemporal pricing with strategic customer behavior," Management Science, vol. 53, no. 5, pp. 726-741, 2007.
[10] Y. Xiong, G. Li, Y. Zhou, K. Fernandes, R. Harrison, and Z. Xiong, "Dynamic pricing models for used products in remanufacturing with lost-sales and uncertain quality," International Journal of Production Economics, vol. 147, pp. 678-688, 2014.

[11] Y. Aviv and A. Pazgal, "Optimal pricing of seasonal products in the presence of forward-looking consumers," Manufacturing \& Service Operations Management, vol. 10, no. 3, pp. 339-359, 2008.

[12] Q. Liu and G. J. Van Ryzin, "Strategic capacity rationing to induce early purchases," Management Science, vol. 54, no. 6, pp. 1115-1131, 2008.

[13] Z. Li and D. Tan, "Two-stage dynamic pricing and advertising strategies for online video services," Discrete Dynamics in Nature and Society, vol. 2017, Article ID 1349315, 8 pages, 2017.

[14] P. K. Pandey, "Solution of two point boundary value problems, a numerical approach: parametric difference method," Applied Mathematics and Nonlinear Sciences, vol. 3, no. 2, pp. 649-658, 2018.

[15] E. Navarro-Pardo, L. González-Pozo, P. Villacampa-Fernández, J. Conejero, and A. Benefits of, "Benefits of a dance group intervention on institutionalized elder people: a Bayesian network approach," Applied Mathematics and Nonlinear Sciences, vol. 3, no. 2, pp. 503-512, 2018.

[16] X. Su and F. Zhang, "On the value of commitment and availability guarantees when selling to strategic consumers," Management Science, vol. 55, no. 5, pp. 713-726, 2009.

[17] G. P. Cachon, "The allocation of inventory risk in a supply chain: push, pull, and advance-purchase discount contracts," Management Science, vol. 50, no. 2, pp. 222-238, 2004.

[18] G. Lai, L. G. Debo, and K. Sycara, "Buy now and match later: impact of posterior price matching on profit with strategic consumers," Manufacturing and Service Operations Management, vol. 12, no. 1, pp. 33-55, 2010.

[19] S. Salop, "Practices that (credibly) facilitate oligopoly coordination," in New Developments in the Analysis of Market Structure, J. Stiglitz and F. Mathewson, Eds., MIT Press, Cambridge, Mass, USA, 1986.

[20] C. A. Holt and D. T. Scheffman, "Facilitating practices: The effects of advance notice and best-price policies," The RAND Journal of Economics, vol. 18, pp. 187-197, 1987.

[21] I. P. Png and D. Hirshleifer, "Price discrimination through offers to match price," The Journal of Business, vol. 60, pp. 365-383, 1987.

[22] Y. Chen, C. Narasimhan, and Z. J. Zhang, "Consumer heterogeneity and competitive price-matching guarantees," Marketing Science, vol. 20, no. 3, pp. 300-314, 2001.

[23] M. Kukar-Kinney, L. Xia, and K. B. Monroe, "Consumers' perceptions of the fairness of price-matching refund policies," Journal of Retailing, vol. 83, no. 3, pp. 325-337, 2007. 
[24] A. Prasad, R. Venkatesh, and V. Mahajan, "Product bundling or reserved product pricing? Price discrimination with myopic and strategic consumers," International Journal of Research in Marketing, vol. 32, no. 1, pp. 1-8, 2015.

[25] M. Kremer, B. Mantin, and A. Ovchinnikov, "Dynamic pricing in the presence of myopic and strategic consumers: theory and experiment," Production \& Operations Management, vol. 26, no. 2, pp. 93-97, 2017.

[26] Z.-J. M. Shen and X. Su, "Customer behavior modeling in revenue management and auctions: a review and new research opportunities," Production and Operations Management, vol. 16, no. 6, pp. 713-728, 2007.

[27] K. J. Arrow, "The economic implications of learning by doing," Review of Economic Studies, vol. 29, no. 3, pp. 155-173, 1962.

[28] S. Rosen, "Learning by experience as joint production," The Quarterly Journal of Economics, vol. 86, no. 3, pp. 366-382, 1972.

[29] M. Pruett and H. Thomas, "Experience-based learning in innovation and production," R\&D Management, vol. 38, no. 2, pp. 141-153, 2008.

[30] J. Y. Jin, J. Perote-Peña, and M. Troege, "Learning by doing, spillovers and shakeouts," Journal of Evolutionary Economics, vol. 14, no. 1, pp. 85-98, 2004.

[31] C. Terwiesch and R. E. Bohn, "Learning and process improvement during production ramp-up," International Journal of Production Economics, vol. 70, no. 1, pp. 1-19, 2001.

[32] S. Erat and S. Kavadias, "Introduction of new technologies to competing industrial customers," Management Science, vol. 52, no. 11, pp. 1675-1688, 2006.

[33] A. Aflaki, P. Feldman, and R. Swinney, Choosing to Be Strategic: Implications of the Endogenous Adoption of Forward-Looking Purchasing Behavior on Multiperiod Pricing, Social Science Electronic Publishing, 2016.

[34] G. P. Cachon and R. Swinney, "Purchasing, pricing, and quick response in the presence of strategic consumers," Management Science, vol. 55, no. 3, pp. 497-511, 2009.

[35] I. Png, Managerial Economics, Routledge, 2013.

[36] N. W. Hatch and D. C. Mowery, "Process innovation and learning by doing in semiconductor manufacturing," Management Science, vol. 44, no. 11 part 1, pp. 1461-1477, 1998.

[37] X. Su and F. Zhang, "Strategic customer behavior, commitment, and supply chain performance," Management Science, vol. 54, no. 10, pp. 1759-1773, 2008. 


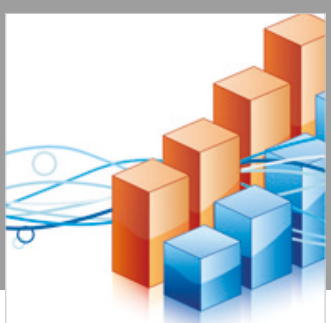

Advances in

Operations Research

\section{-n-m}
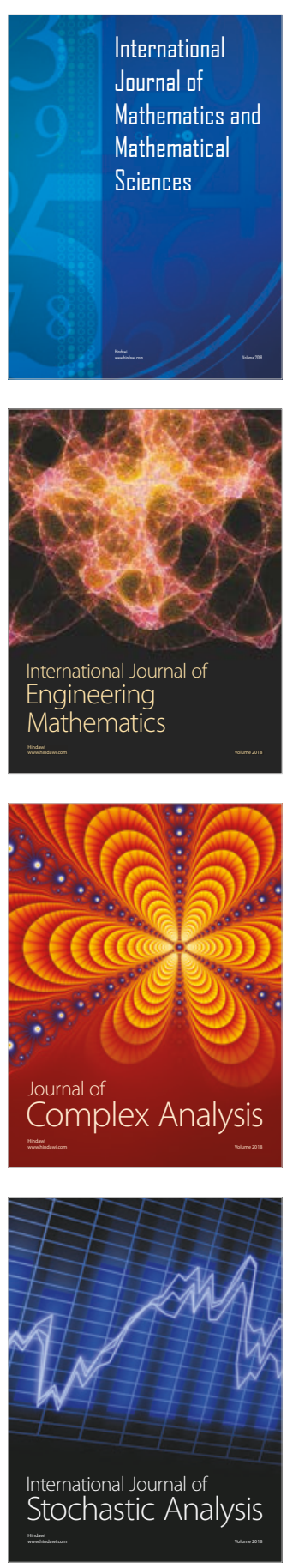
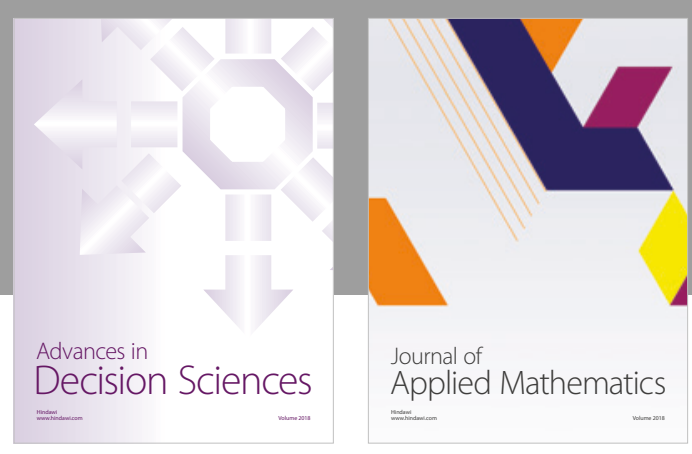

Journal of

Applied Mathematics
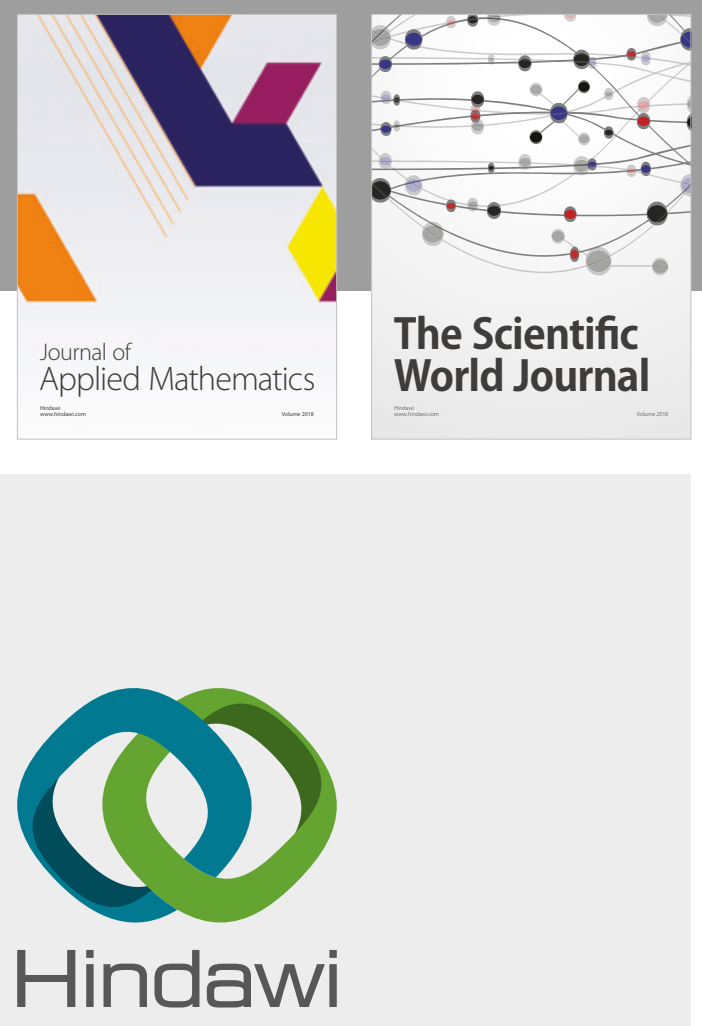

Submit your manuscripts at

www.hindawi.com

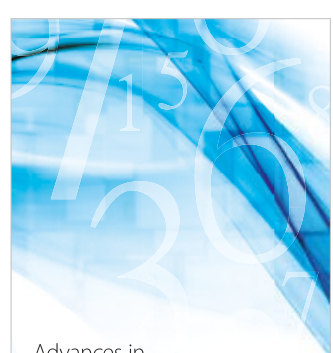

Advances in
Numerical Analysis
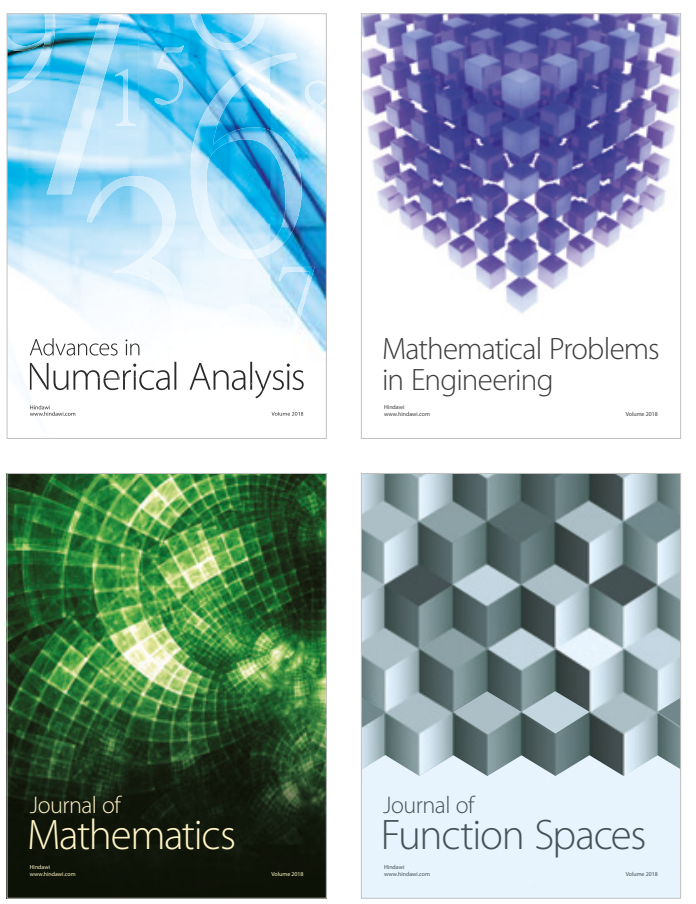

Mathematical Problems in Engineering

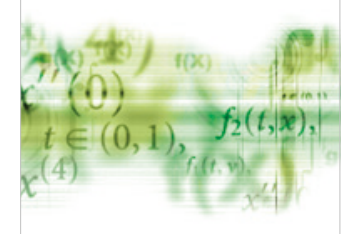

International Journal of

Differential Equations

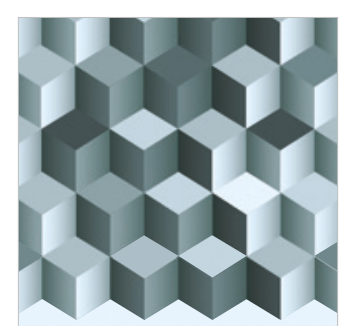

Journal of

Function Spaces
The Scientific

World Journal

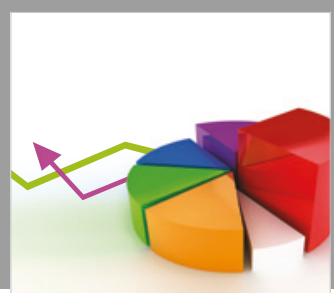

Journal of

Probability and Statistics
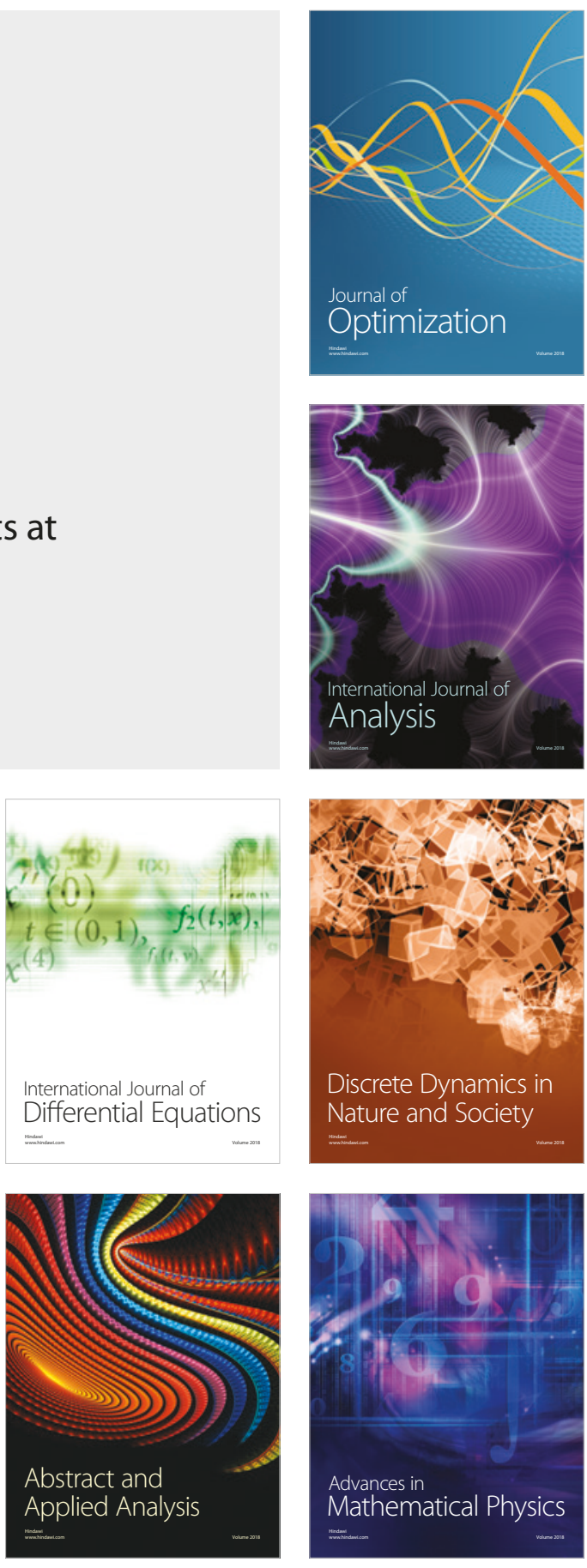